\title{
A MESSAGE FROM THE STANDARDS ASSOCIATION OF NEW ZEALAND
}

G. H. Edwards*

The Standards Association has a distinguished ancestry. All closely associated with a national building code.

The Standards Institution, formed in 1932 under the wing of NZIE (then the NZ Society of Civil Engineers), started the development of the first code, NZS 95. This was extended and developed by the NZ Standards Institute (part of DSIR and later a division of the Department of Industries \& Commerce)... and was developed further as NZS 1900. This independent standards Association (SANZ), formed in 1966, is proud to continue this work.

These codes have been evolved by the "Standards" method of discussion and agreement at meetings of committees of representatives of all major interests; this process is described more fully in the code Feature section of this issue.

On behalf of the Association, may I welcome the contribution of the Society of Earthquake Engineering to the development of building codes by the introduction of the code Feature Section? It is hoped that developments in NZS 1900 discussed by SANZ Chief Technical Adviser, Mr E. H. Hitchcock, in this issue will contribute to the vigour and flexibility of New Zealand's national building code, and that members of the society will play their full part in these developments.

*Director, Standards Association of New Zealand. 